\title{
The Crystal Structure and Absolute Configuration of the Methiodide of the Alkaloid Cryptostyline I*
}

\author{
L E I F W E S T I N
}

Institute of Inorganic and Physical Chemistry, University of Stockholm, Box 6801, S.11386 Stockholm, Sweden

\begin{abstract}
The crystal structure of the methiodide of 1-(3,4-methylenedioxyphenyl)-2-methyl-6,7-dimethoxy-1,2,3,4-tetrahydroisoquinoline, $\mathrm{C}_{20} \mathrm{H}_{24} \mathrm{INO}_{4}$, has been determined by the heavy atom method and the parameters of non-hydrogen atoms have been refined by leastsquares techniques. The unit cell is orthorhombic, space group $P 2_{1} 2_{1} 2_{1}$, with $a=18.093, b=11.941, c=9.227 \AA$, and $Z=4$. The absolute configuration of the optically active molecule has been determined by use of anomalous dispersion of $\mathrm{Cu} K \alpha$ radiation by the iodine atom. The final $R$ index was 0.05 for a selected group of 780 from a total number of 952 independent reflections.
\end{abstract}

1-(3-4-Methylenedioxyphenyl)-2-methyl-6,7-dimethoxy-1, 2, 3, 4-tetrahydroisoquinoline, cryptostyline I, has together with two closely related alkaloids, cryptostyline II and III, been isolated from the plant Cryptostylis fulva, Schltr. by Leander et al. ${ }^{1}$ The plant was collected around Bupu Village, Wampit, Territory of New Guinea.

The constitution of the optically active cryptostylines I, II, and III was suggested by spectral methods and confirmed by synthesis. The three molecular formulae, given in Fig. 1, differ in the substitution pattern of the 1-phenyl

Fig. 1. Molecular structure of: cryptostyline I, $\mathbf{R}_{1}=\mathrm{H}, \quad \mathrm{R}_{2} \mathrm{R}_{3}=\mathrm{O}-\mathrm{CH}_{2}-\mathrm{O}$; cryptostyline II, $\mathrm{R}_{1}=\mathrm{H}, \mathrm{R}_{2}=\mathrm{R}_{3}=\mathrm{OCH}_{3}$; cryptostyline III, $\mathrm{R}_{1}=\mathrm{R}_{2}=\mathrm{R}_{3}=\mathrm{OCH}_{3}$. The figures within the carbon rings are used in the systematic names of the compounds.

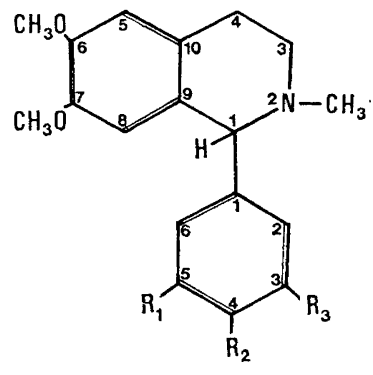

* Work reported at the 7:e Nordiska Strukturkemistmötet (7th Meeting of Nordic Structural Chemists), Göteborg 1970, p. 112 .

Acta Chem. Scand. 26 (1972) No. 6 
group, being 3,4-methylenedioxy, 3,4-dimethoxy, and 3,4,5-trimethoxy, respectively. However, it was not possible to determine the absolute configuration by optical circular dichroism or by any other spectral method. For this reason an $\mathrm{X}$-ray study of cryptostyline $\mathrm{I}$ was undertaken to establish the stereochemistry of the 1-phenyl-1,2,3,4-tetrahydroisoquinolines.

\section{EXPERIMENTAL}

The methiodide of cryptostyline I was synthesized by Leander et al..$^{1}$ Crystals of this compound were obtained by slow cooling of a saturated ethanol solution.

Powder photographs were taken in a Guinier focusing camera with $\mathrm{CuK \alpha _{1 }}$ radiation and potassium chloride as an internal standard. The dimensions of the orthorhombic unit cell derived from these data were $a=18.093 \pm 1, b=11.941 \pm 1$, and $c=9.227 \pm 1 \AA$. The observed density $1.558 \mathrm{~g} \mathrm{~cm}^{-3}$, obtained by flotation in a mixture of chloroform and carbon tetrachloride, indicated that the unit cell contains 4 formula units of $\mathrm{C}_{20} \mathrm{H}_{24} \mathrm{INO}_{4}$, the calculated density being $1.563 \mathrm{~g} \mathrm{~cm}^{-3}$.

A crystal with the dimensions $0.03 \times 0.07 \times 0.21 \mathrm{~mm}^{3}$ was used for the collection of $\mathrm{X}$-ray diffraction data. With the axial directions chosen above, the axis parallel to the longest edge of the crystal was the $c$ axis and the axis parallel to the shortest edge the $a$ axis. The crystal showed well developed faces parallel to the planes $\{100\}$ and $\{210$.

Weissenberg photographs were taken with the crystal rotating around the $b$ and $c$ axes. Systematic absences in the $h 00,0 k 0$, and $00 l$ reflections on these photographs uniquely determined the space group as $P 2_{1} 2_{1} 2_{1}$.

T'able 1. Parameters of non-hydrogen atoms and their estimated standard deviations.

I

$$
\begin{gathered}
x \\
0.5094 \pm 1 \\
b_{33} \\
0.0113 \pm 2 \\
x
\end{gathered}
$$

$\mathrm{O}(1)$

$\mathrm{O}(2)$

$\mathrm{O}(3)$

$\mathrm{O}(4)$

$\mathrm{N}$

C(1)

$\mathrm{C}(2)$

$\mathrm{C}(3)$

C(4)

$\mathrm{C}(5)$

C(6)

C(7)

$\mathrm{C}(8)$

$\mathrm{C}(9)$

C(10)

$\mathrm{C}(11)$

$\mathrm{C}(12)$

$\mathrm{C}(13)$

C(14)

C(15)

$\mathrm{C}(16)$

C(17)

$\mathrm{C}(18)$

C(19)

$\mathrm{C}(20)$
$0.1642+7$

$0.2978 \pm 6$

$0.1442 \pm 6$

$0.3321 \pm 7$

$0.4431 \pm 7$

$0.399 \pm 1$

$0.376+1$

$0.360 \pm 1$

$0.332 \pm 1$

$0.325 \pm 1$

$0.340 \pm 1$

$0.365 \pm 1$

$0.377 \pm 1$

$0.401 \pm 1$

$0.338 \pm 1$

$0.351 \pm 1$

$0.293 \pm 1$

$0.228 \pm 1$

$0.214 \pm 1$

$0.266 \pm 1$

$0.107 \pm 1$

$0.515 \pm 1$

$0.465 \pm 1$

$0.279 \pm 1$

$0.354 \pm 1$ $\stackrel{y}{0.2774} \pm 1$

$b_{12}$

$-0.0020 \pm 1$

$$
y
$$

$0.524 \pm 1$

$-0.212 \pm 1$

$0.377 \pm 1$

$-0.107 \pm 1$

$0.255 \pm 1$

$0.228 \pm 2$

$0.102 \pm 2$

$0.054 \pm 1$

$-0.060 \pm 1$

$-0.107 \pm 2$

$-0.048 \pm 2$

$0.062 \pm 1$

$0.111 \pm 1$

$0.232 \pm 2$

$0.310 \pm 1$

$0.406 \pm 2$

$0.479 \pm 2$

$0.465 \pm 1$

$0.374 \pm 1$

$0.294 \pm 1$

$0.472 \pm 2$

$0.188 \pm 1$

$0.381 \pm 1$

$-0.274 \pm 2$

$-0.053 \pm 2$

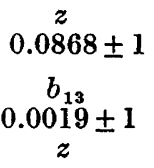

$0.823 \pm 1$

$0.758 \pm 1$

$0.666 \pm 1$

$0.991 \pm 1$

$0.586 \pm 2$

$0.446 \pm 2$

$0.444 \pm 3$

$0.601 \pm 2$

$0.607 \pm 2$

$0.737 \pm 2$

$0.867 \pm 2$

$0.861 \pm 2$

$0.723 \pm 2$

$0.721 \pm 2$

$0.746 \pm 2$

$0.844 \pm 2$

$0.877 \pm 2$

$0.818+2$

$0.721 \pm 2$

$0.682+2$

$0.733 \pm 3$

$0.587 \pm 2$

$0.571 \pm 2$

$0.622 \pm 3$

$1.124 \pm 2$ $b_{11}$
$0.0043 \pm 1$
$b_{23}$
$0.0010 \pm 3$
$B$

$5.2 \pm 3$

$5.3 \pm 3$

$4.4 \pm 3$

$4.5 \pm 3$

$4.3 \pm 3$

$4.5 \pm 4$

$5.4+5$

$2.8 \pm 3$

$3.7 \pm 4$

$3.5 \pm 4$

$3.4 \pm 4$

$3.7 \pm 4$

$2.6 \pm 4$

$3.9 \pm 4$

$3.5 \pm 4$

$5.1 \pm 5$

$4.3 \pm 4$

$3.9 \pm 4$

$3.6 \pm 4$

$3.3 \pm 4$

$5.6 \pm 5$

$5.6 \pm 4$

$5.0 \pm 4$

$7.8 \pm 6$

$5.5 \pm 5$ 
Table 2. Observed and calculated structure factors and their phase angles.

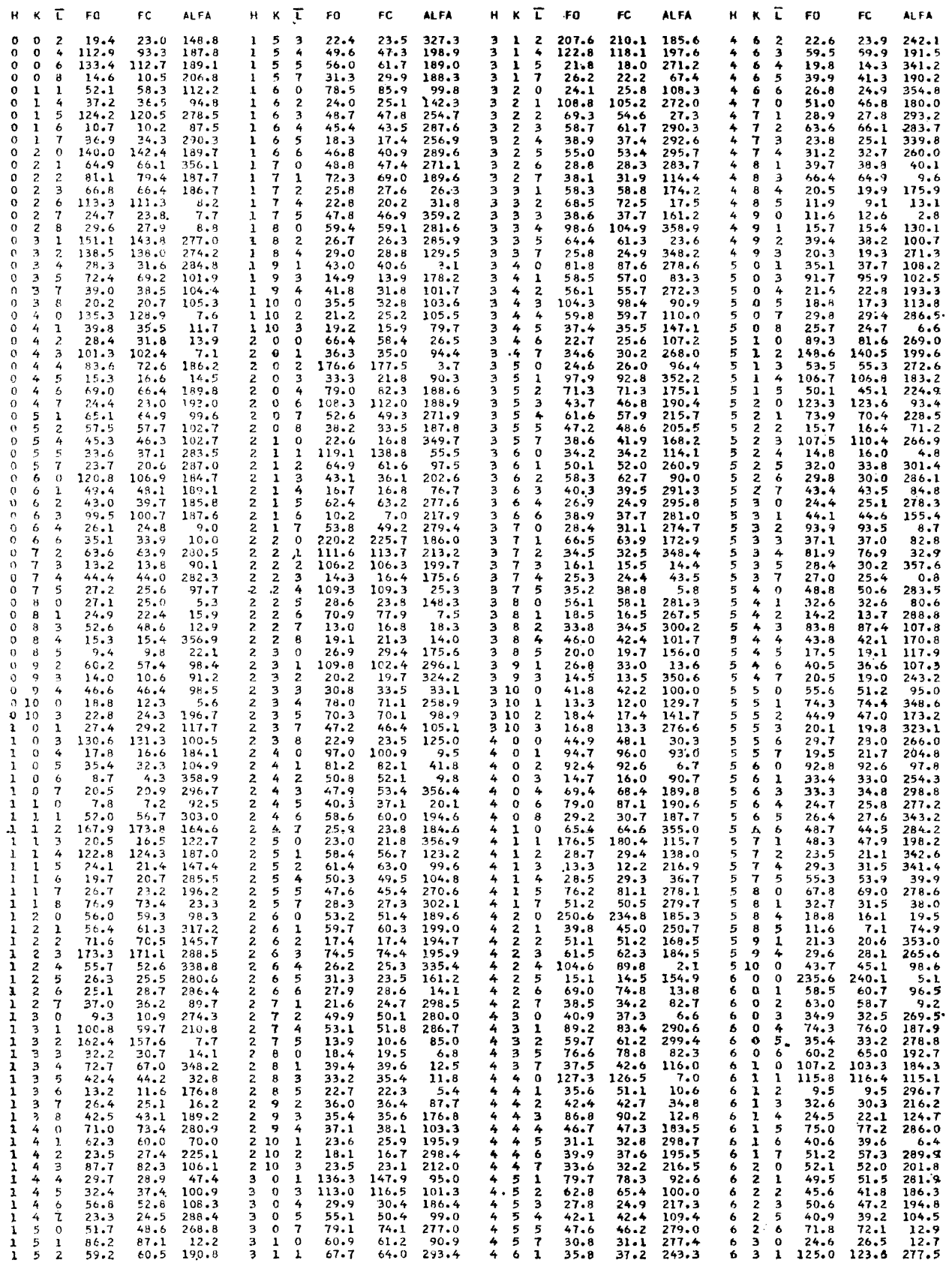

Acta Chem. Scand. 26 (1972) No. 6 
Table 2. Continued.

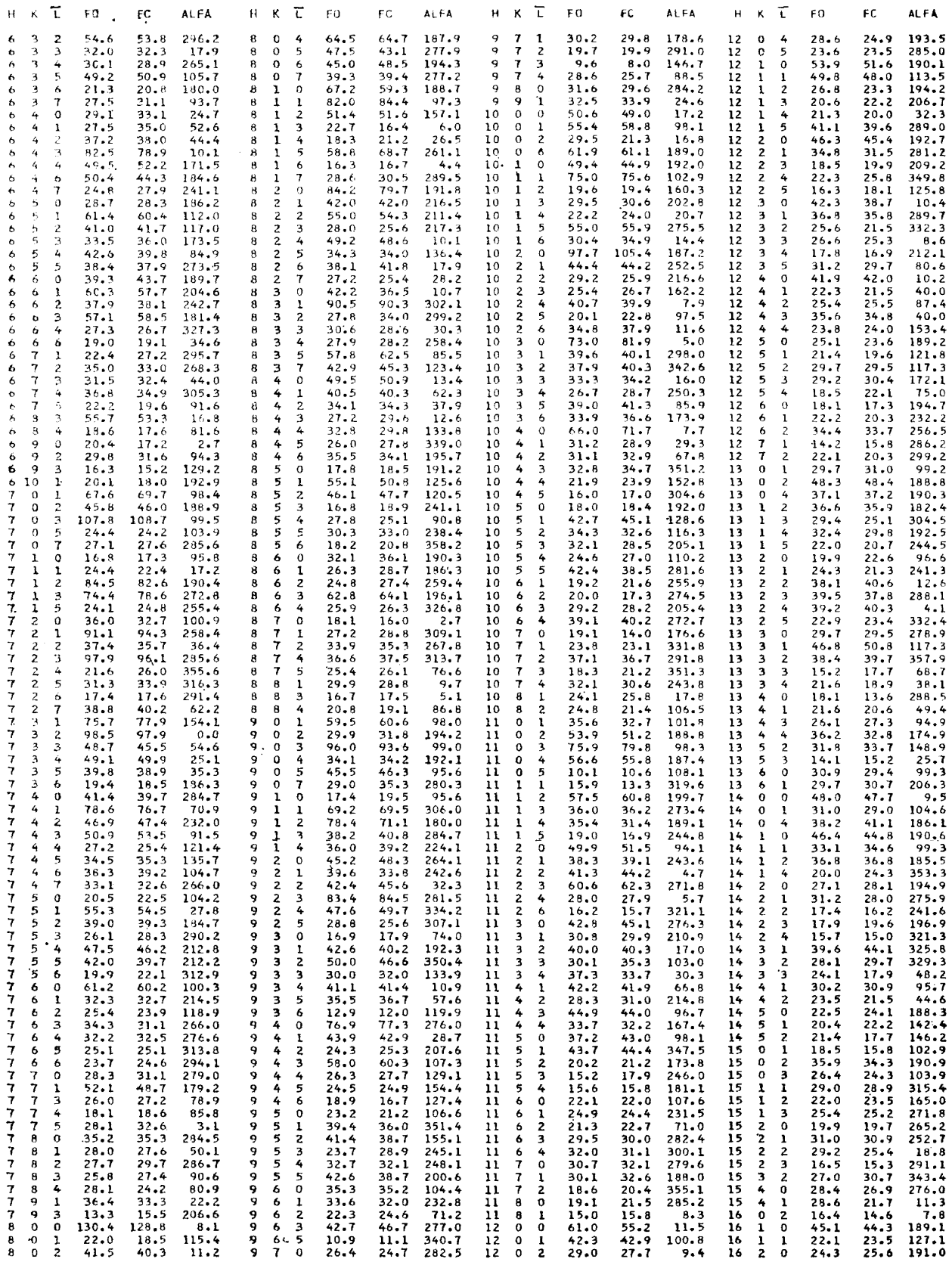


The single crystal was mounted on a Siemens automatic diffractometer with a scintillation detector and a pulse-height analyser. Nickel-filtered $\mathrm{Cu} K \alpha$ radiation, $\theta-2 \theta$ scanning, and a five-value measuring technique were used to record 952 reflections with $\theta \leq 45^{\circ}$. The intensities of 780 reflections with $\sigma(I)<0.3 I$ were used in the structure determination. The intensities were corrected for $\mathrm{Lp}$ and absorption effects $\left(\mu=128 \mathrm{~cm}^{-1}\right)$.

A list of all crystallographic programs used for the determination of the structure of cryptostyline $I$ is given in Table 6 .

\section{STRUCTURE DETERMINATION AND REFINEMENT}

Approximate coordinates of the iodine atom were derived from Harker sections at $u=\frac{1}{2}, v=\frac{1}{2}$, and $w=\frac{1}{2}$, respectively. The coordinates of the iodine atom $(x=0.51, y=0.28$, and $z=0.09)$ were refined by least-squares technique to an $R$ value of 0.37 . A three-dimensional difference Fourier synthesis calculated with the phases from the iodine atom revealed 34 peaks. Because the atom is rather close to a special position, there appeared nine pseudo mirror image peaks related to the real ones by the planes of symmetry at $x=0$ and $\frac{1}{2}$. 14 peaks were then picked out from the first difference Fourier synthesis, all related by reasonable distances and angles. New difference Fourier syntheses were then calculated by which the remaining atoms step by step were located and included in the calculation $(R=0.30)$.

The position parameters of all non-hydrogen atoms were then refined by least-squares techniques and with anisotropic temperature parameters for the iodine atom. Correction for anomalous dispersion by the iodine atom was also included. Hughes' weighting procedure with $\left|F_{\min }\right|=15$ was applied and the refinement was continued until the shifts in the atomic parameters were less than $10 \%$ of their standard deviations. The atomic parameters and their standard deviations are given in Table 1 and the observed and calculated structure factors in Table 2.

\section{ABSOLUTE CONFIGURATION}

The absolute configuration of cryptostyline I was determined by the anomalous dispersion method. ${ }^{2}$ The value of the imaginary dispersion correction term of the scattering factor of the iodine atom was taken as $\Delta f^{\prime \prime}=6.68$ (International Tables for $X$-Ray Crystallography, 1962). Observed and calculated structure factor ratios of some Bijvoet pairs are given in Table 3 . The final calculated $R$ index was 0.053 for the correct absolute configuration shown in Fig. 2. Structure factors of the other form of the enantiomorphic structures were calculated from a new set of position parameters. In this set the signs of one of the $x, y$, or $z$ parameters were changed for all atoms. The $R$ index for the latter enantiomorphic structure was 0.07 . Thus, the absolute configuration obtained from a study of Bijvoet pairs and the one obtained from the best fit of the structure factors are in agreement.

\section{DESCRIPTION AND DISCUSSION OF THE STRUCTURE}

The crystal structure determination shows that the molecular formula given by Leander et al. ${ }^{1}$ is correct. The molecule is built of a substituted isoquinoline group and a 3,4-methylenedioxyphenyl group. These are connected 
Table 3. Observed and calculated structure factor ratios of some Bijvoet pairs of reflec. tions used for the establishment of the absolute configuration.

\begin{tabular}{|c|c|c|}
\hline$h k l$ & $\left|F_{\mathrm{o}}(h k l)\right| /\left|F_{\mathrm{o}}(h k \bar{l})\right|$ & $\left|F_{\mathrm{c}}(h k l)\right| /\left|F_{\mathrm{c}}(h k \bar{l})\right|$ \\
\hline 111 & 0.82 & 0.89 \\
\hline 112 & 0.95 & 0.92 \\
\hline 113 & 0.91 & 0.91 \\
\hline 114 & 0.88 & 0.99 \\
\hline 115 & 0.82 & 0.80 \\
\hline 116 & 0.80 & 0.85 \\
\hline 117 & 1.05 & 1.06 \\
\hline 121 & 1.39 & 1.34 \\
\hline 122 & 1.13 & 1.12 \\
\hline 124 & 1.21 & 1.19 \\
\hline 212 & 0.90 & 0.97 \\
\hline 214 & 0.80 & 0.87 \\
\hline 223 & 0.69 & 0.65 \\
\hline 224 & 1.18 & 1.09 \\
\hline 231 & 1.11 & 1.09 \\
\hline 233 & 0.97 & 0.98 \\
\hline
\end{tabular}

at atom $\mathrm{C}(9)$ which also binds one hydrogen atom (Fig. 2). The isoquinoline group is found to be almost perpendicular to the $x y$-plane. This is illustrated in the packing diagram of the molecular crystal viewed along the $c$ axis (Fig. 3 ). The atoms in the 3,4-methylenedioxyphenyl group are found close to another plane. The least-squares planes of these two planes including the atoms $\mathrm{C}(3) \mathrm{C}(4) \mathrm{C}(5) \mathrm{C}(6) \mathrm{C}(7) \mathrm{C}(8)$ and $\mathrm{C}(10) \mathrm{C}(11) \mathrm{C}(12) \mathrm{C}(13) \mathrm{C}(14) \mathrm{C}(15)$, respectively, were calculated. The distances of the atoms from these planes given

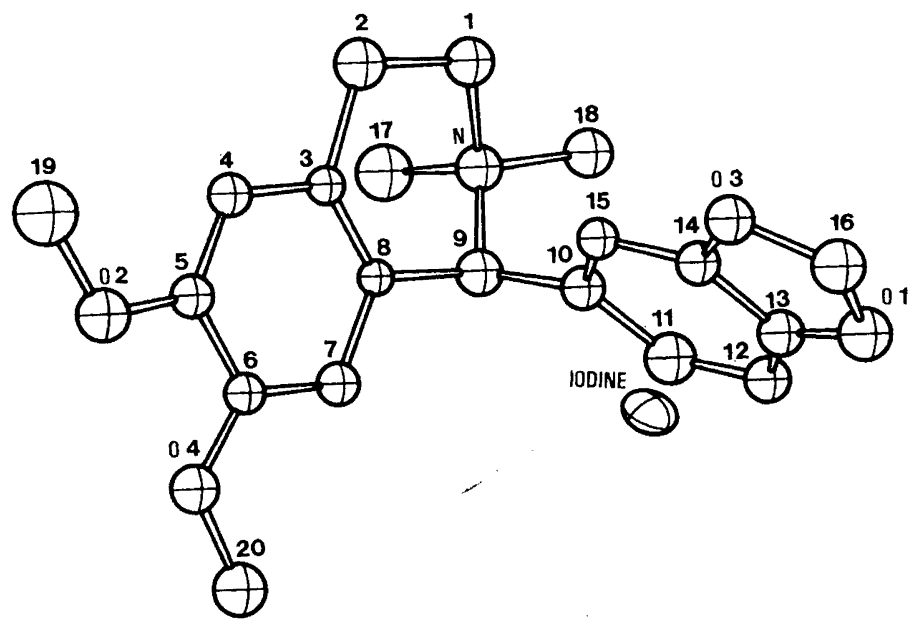

Fig. 2. The molecular structure and absolute configuration of cryptostyline I viewed along [100]. 


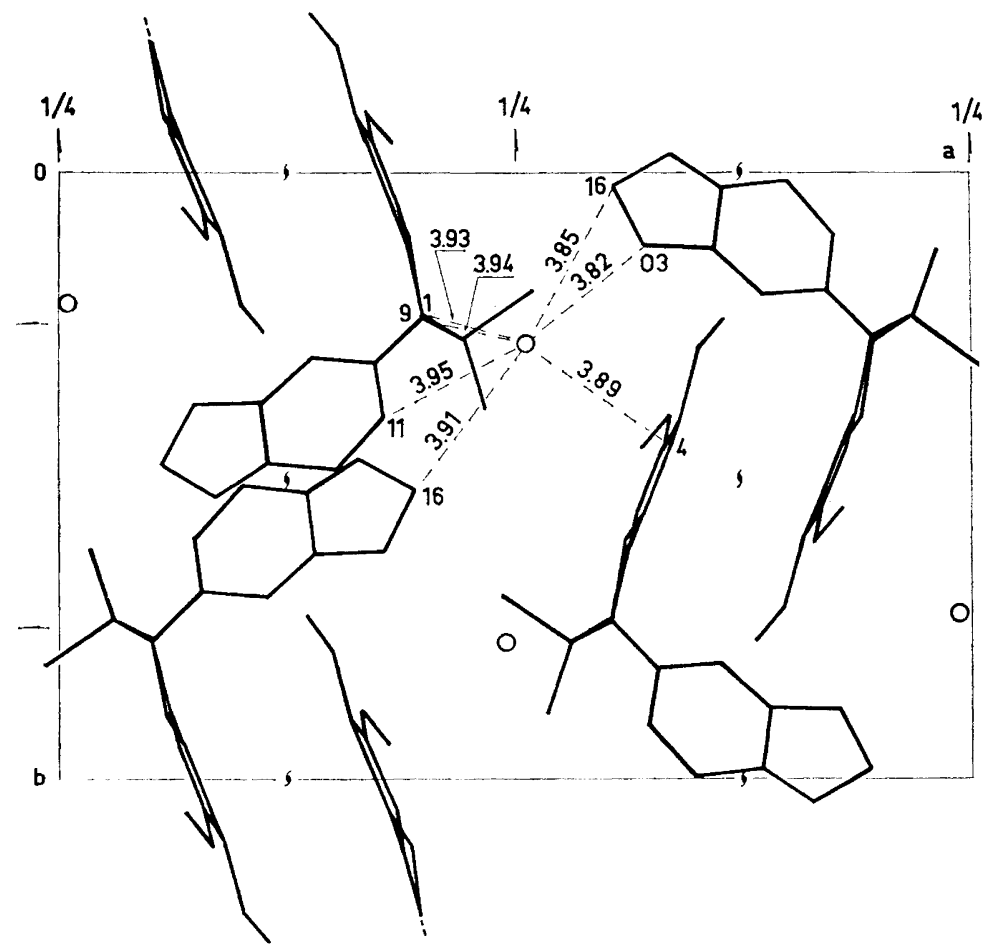

Fig. 3. The packing diagram of cryptostyline I viewed along [001]. The isoquinoline group is found to be almost perpendicular to the $x y$ plane. Distances less than $4 \AA$ between iodine and its neighbour atoms are denoted by dashed lines.

Table 4. Least-squares planes. The coefficients $q_{\mathrm{i}}$ are direction cosines relative to $a, b$, and $c ; D$ is the origin-to-plane distance. The first six atoms in the calculations of plane I and II are defining the plane.

\begin{tabular}{llccrrr}
\hline Plane I & Atom & Deviation & Plane II & Atom & Deviation \\
\hline$q_{1}=0.270$ & $\mathrm{C}(10)$ & $-0.01 \AA$ & $q_{1}=0.940$ & $\mathrm{C}(3)$ & $0.00 \AA$ \\
$q_{2}=0.567$ & $\mathrm{C}(11)$ & 0.01 & $q_{2}=-0.341$ & $\mathrm{C}(4)$ & -0.01 \\
$q_{3}=0.778$ & $\mathrm{C}(12)$ & -0.01 & $q_{3}=0.027$ & $\mathrm{C}(5)$ & 0.01 \\
$D=5.573$ & $\mathrm{C}(13)$ & 0.00 & $D=0.006$ & $\mathrm{C}(6)$ & 0.00 \\
& $\mathrm{C}(14)$ & 0.01 & & & $\mathrm{C}(7)$ & -0.02 \\
& $\mathrm{C}(15)$ & 0.00 & & & $\mathrm{C}(8)$ & 0.02 \\
& $\mathrm{O}(1)$ & 0.05 & & & $\mathrm{C}(1)$ & -0.02 \\
& $\mathrm{O}(3)$ & 0.08 & & $\mathrm{C}(2)$ & 0.10 \\
& $\mathrm{C}(16)$ & 0.06 & & $\mathrm{C}(19)$ & -0.06 \\
& & & & $\mathrm{C}(20)$ & 0.19 \\
& & & & $\mathrm{O}(2)$ & -0.02 \\
& & & & $\mathrm{O}(4)$ & 0.08 \\
\hline
\end{tabular}

Acta Chem. Scand. 26 (1972) No. 6 
in Table 4 show that the two benzene rings are almost planar. However, the two methoxy groups, $\mathrm{O}(2)-\mathrm{C}(19)$ and $\mathrm{O}(4)-\mathrm{C}(20)$, are slightly twisted out of the plane of the first benzene ring, and the three atoms $\mathrm{O}(1)-\mathrm{C}(16)-\mathrm{O}(3)$, forming the methylenedioxy bridge, are displaced about $0.06 \AA$ from the plane of the second benzene ring.

The mean values of the distances in the phenyl groups, $1.40 \AA$, are in agreement with the value given by Pauling ${ }^{3}$ ( $1.397 \AA$ ). The distances between the carbon atoms in the $\mathrm{NC}(1) \mathrm{C}(2) \mathrm{C}(3) \mathrm{C}(8) \mathrm{C}(9)$ ring with the $s p^{3}-s p^{3}$ bonds

Table 5. Interatomic distances and angles for non-hydrogen atoms in cryptostyline I and their standard deviations.

Code for symmetry-related atoms

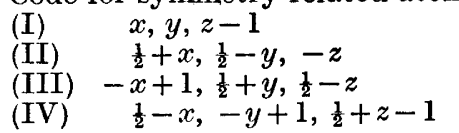

$\mathrm{I}-\mathrm{O}(3)(\mathrm{II})$
$\mathrm{C}(16)(\mathrm{II})$
$\mathrm{C}(4)(\mathrm{III})$
$\mathrm{C}(16)(\mathrm{IV})$
$\mathrm{C}(1)$
$\mathrm{C}(9)(\mathrm{I})$
$\mathrm{C}(11)(\mathrm{I})$
$\mathrm{O}(1)-\mathrm{C}(13)$
$\mathrm{C}(16)$
$\mathrm{O}(2)-\mathrm{C}(5)$
$\mathrm{C}(19)$
$\mathrm{O}(3)-\mathrm{C}(14)$
$\mathrm{C}(16)$
$\mathrm{O}(4)-\mathrm{C}(6)$
$\mathrm{C}(20)$
$\mathrm{N}-\mathrm{C}(9)$
$\mathrm{C}(17)$
$\mathrm{C}(1)$
$\mathrm{C}(13)-\mathrm{O}(1)-\mathrm{C}(16)$
$\mathrm{C}(5)-\mathrm{O}(2)-\mathrm{C}(19)$
$\mathrm{C}(14)-\mathrm{O}(3)-\mathrm{C}(16)$
$\mathrm{C}(6)-\mathrm{O}(4)-\mathrm{C}(20)$
$\mathrm{C}(1)-\mathrm{N}-\mathrm{C}(9)$
$\mathrm{C}(1)-\mathrm{N}-\mathrm{C}(17)$
$\mathrm{C}(1)-\mathrm{N}-\mathrm{C}(18)$
$\mathrm{C}(9)-\mathrm{N}-\mathrm{C}(17)$
$\mathrm{C}(9)-\mathrm{N}-\mathrm{C}(18)$
$\mathrm{C}(17)-\mathrm{N}-\mathrm{C}(18)$
$\mathrm{N}-\mathrm{C}(1)-\mathrm{C}(2)$
$\mathrm{C}(1)-\mathrm{C}(2)-\mathrm{C}(3)$
$\mathrm{C}(2)-\mathrm{C}(3)-\mathrm{C}(4)$
$\mathrm{C}(2)-\mathrm{C}(3)-\mathrm{C}(8)$
$\mathrm{C}(4)-\mathrm{C}(3)-\mathrm{C}(8)$
$\mathrm{C}(3)-\mathrm{C}(4)-\mathrm{C}(5)$
$\mathrm{O}(2)-\mathrm{C}(5)-\mathrm{C}(4)$
$\mathrm{O}(2)-\mathrm{C}(5)-\mathrm{C}(6)$
$\mathrm{C}(4)-\mathrm{C}(5)-\mathrm{C}(6)$
$\mathrm{O}(4)-\mathrm{C}(6)-\mathrm{C}(5)$
$\mathrm{O}(4)-\mathrm{C}(6)-\mathrm{C}(7)$

$3.82 \pm 1$
$3.85 \pm 2$
$3.89 \pm 2$
$3.91 \pm 2$
$3.93 \pm 2$
$3.94 \pm 2$
$3.95 \pm 2$
$1.36 \pm 2$
$1.45 \pm 2$
$1.37 \pm 2$
$1.50 \pm 3$
$1.35 \pm 2$
$1.46 \pm 2$
$1.35 \pm 2$
$1.45 \pm 3$
$1.49 \pm 2$
$1.53 \pm 3$
$1.55 \pm 3$
$111 \pm 2$
$115 \pm 1$
$107 \pm 1$
$117 \pm 1$
$113 \pm 2$
$110 \pm 2$
$105 \pm 2$
$110 \pm 2$
$112 \pm 2$
$107 \pm 2$
$110 \pm 2$
$113 \pm 2$
$117 \pm 2$
$123 \pm 2$
$121 \pm 2$
$118 \pm 2$
$123 \pm 2$
$114 \pm 2$
$123 \pm 2$
$115 \pm 2$
$125 \pm 2$

\begin{tabular}{|c|c|}
\hline $\mathrm{N}-\mathrm{C}(18)$ & $1.55 \pm 2 A$ \\
\hline $\mathrm{C}(1)-\mathrm{C}(2)$ & $1.56 \pm 3$ \\
\hline $\mathrm{C}(2)-\mathrm{C}(3)$ & $1.57 \pm 3$ \\
\hline $\mathrm{C}(3)-\mathrm{C}(8)$ & $1.35 \pm 2$ \\
\hline $\mathrm{C}(4)$ & $1.46 \pm 2$ \\
\hline$C(4)-C(5)$ & $1.33 \pm 3$ \\
\hline $\mathrm{C}(5)-\mathrm{C}(6)$ & $1.41 \pm 3$ \\
\hline$C(6)-C(7)$ & $1.39 \pm 3$ \\
\hline$C(7)-C(8)$ & $1.41 \pm 2$ \\
\hline$C(8)-C(9)$ & $1.50 \pm 3$ \\
\hline $\mathrm{C}(9)-\mathrm{C}(10)$ & $1.51 \pm 3$ \\
\hline$C(10)-C(15)$ & $1.42 \pm 2$ \\
\hline $\mathrm{C}(11)$ & $1.47 \pm 3$ \\
\hline$C(11)-C(12)$ & $1.40 \pm 3$ \\
\hline $\mathrm{C}(12)-\mathrm{C}(13)$ & $1.32 \pm 3$ \\
\hline$C(13)-C(14)$ & $1.43 \pm 3$ \\
\hline$C(14)-C(15)$ & $1.38 \pm 2$ \\
\hline$C(5)-C(6)-C(7)$ & $119 \pm 2^{\circ}$ \\
\hline$C(6)-C(7)-C(8)$ & $119 \pm 2$ \\
\hline $\mathrm{C}(3)-\mathrm{C}(8)-\mathrm{C}(7)$ & $120 \pm 2$ \\
\hline $\mathrm{C}(3)-\mathrm{C}(8)-\mathrm{C}(9)$ & $122 \pm 2$ \\
\hline $\mathrm{C}(7)-\mathrm{C}(8)-\mathrm{C}(9)$ & $117 \pm 2$ \\
\hline $\mathrm{N}-\mathrm{C}(9)-\mathrm{C}(8)$ & $110 \pm 2$ \\
\hline $\mathrm{N}-\mathrm{C}(9)-\mathrm{C}(10)$ & $114 \pm 2$ \\
\hline$C(8)-C(9)-C(10)$ & $112 \pm 2$ \\
\hline$C(9)-C(10)-C(11)$ & $117 \pm 2$ \\
\hline $\mathrm{C}(9)-\mathrm{C}(10)-\mathrm{C}(15)$ & $123 \pm 2$ \\
\hline$C(11)-C(10)-C(15)$ & $120 \pm 2$ \\
\hline$C(10)-C(11)-C(12)$ & $120 \pm 2$ \\
\hline $\mathrm{C}(11)-\mathrm{C}(12)-\mathrm{C}(13)$ & $120 \pm 2$ \\
\hline $\mathrm{O}(1)-\mathrm{C}(13)-\mathrm{C}(12)$ & $133 \pm 2$ \\
\hline $\mathrm{O}(1)-\mathrm{C}(13)-\mathrm{C}(14)$ & $105 \pm 2$ \\
\hline$C(12)-C(13)-C(14)$ & $121 \pm 2$ \\
\hline $\mathrm{O}(3)-\mathrm{C}(14)-\mathrm{C}(13)$ & $112 \pm 2$ \\
\hline $\mathrm{O}(3)-\mathrm{C}(14)-\mathrm{C}(15)$ & $125 \pm 2$ \\
\hline $\mathrm{C}(13)-\mathrm{C}(14)-\mathrm{C}(15)$ & $123 \pm 2$ \\
\hline$C(10)-C(15)-C(14)$ & $116 \pm 2$ \\
\hline $\mathrm{O}(1)-\mathrm{C}(16)-\mathrm{O}(3)$ & $105 \pm 1$ \\
\hline
\end{tabular}

Acta Chem. Scand. 26 (1972) No. 6 
Table 6. Computer programs used for the crystallographic calculations. All programs are written in FORTRAN IV.

1. LAZY. Calculation of $\sin ^{2} \theta$ - and $d$ values from the measured reflexion sites of a Guinier powder photograph after internal standard correction. IBM $360 / 75$, IBM 1800.

2. PIRUM. Indexing of powder photographs and least squares refinement of unit cell parameters. IBM 1800.

3. SIP. Generation of steering paper tape for SIEMENS AED. IBM 360/75.

4. SIMSA. Interpretation of output on paper tape from SIEMENS AED and evaluation of intensities. IBM 1800.

5. DATAP2. Lp- and absorption corrections. Preparative calculations for extinction correction according to Zachariasen's 1963-formula. IBM 360/ 75.

6. DRF. Fourier summations and structure factor calculations. IBM 360/75.

7. SFLS. Block diagonal least squares refinement of positional and isotropic thermal parameters and of scale factors. IBM 360/75, IBM 1800.

8. LALS. Full matrix least squares refinement of positional and thermal parameters and of scale factors. IBM 360/75.

9. DISTAN. Calculation of interatomic distances and bond angles with estimated standard deviations. IBM $360 / 75$.

10. INERT. Least-squares plane and axes of inertia (usable for plots of molecular structure). IBM 1800.

11. ORTEP. Thermal-ellipsoid plot. For crystal structure illustrations. IBM $360 / 75$.

Acta Chem. Scand. 26 (1972) No. 6
A. G. Nord, Stockholm, Sweden.

P.-E. Werner, Stockholm, Sweden.

R. Norrestam, Stockholm, Sweden.

R. Norrestam, Stockholm, Sweden.

P. Coppens, L. Leiserowitz and D. Rabinovich, Rehovoth, Israel. Modified by $\mathrm{O}$. Olofsson and M. Elfström, Uppsala, Sweden. Inclusion of calculations for extinction correction by B. G. Brandt and S. Åsbrink, Stockholm, Sweden. Further modifications by B. G. Brandt and A. G. Nord, Stockholm, Sweden.

A. Zalkin, Berkeley, USA. Modified by R. Liminga and J.-O. Lundgren, Uppsala, Sweden. Further modified by O. Lindgren, Göteborg, and by A. G. Nord and B. G. Brandt, Stockholm, Sweden.

S. Åsbrink, Stockholm, and C.-I. Brändén, Uppsala, Sweden. Modified and extended by B. G. Brandt, Stockholm, Sweden.

P. K. Gantzel, R. A. Sparks and K. N. Trueblood, Los Angeles, USA. Modified by A. Zalkin, Berkeley, USA, and by J.-O. Lundgren, R. Liminga and C.-I. Brändén, Uppsala, Sweden. Further modified by $\mathrm{O}$. Lindgren, Göteborg, and by $\mathrm{B}$. G. Brandt and A. G. Nord, Stockholm, Sweden.

A. Zalkin, Berkeley, USA. Modified by A. G. Nord and B. G. Brandt, Stockholm, Sweden.

R. Norrestam, Stockholm, Sweden.

C. K. Johnson, Oak Ridge, USA. Modified by I. Carlbom, Stockholm, Sweden. 
are about $1.54 \AA$ (Pauling $1.546 \AA$ ). The oxygen to phenyl carbon distance is short, $1.35 \AA$, and the oxygen to methyl carbon is longer, $1.47 \AA$ (Pauling $1.45 \AA$ ). Calculated distances are given in Table 5 .

The bond angles around $\mathrm{C}(9)$ and the nitrogen atom are close to the tetrahedral value of $109 .{ }^{\circ}$. However, in $N-C(9)-C(10)$ and $C(1)-N-C(18)$ the deviations are about four degrees. The calculated standard deviations of the interatomic distances and the bond angles are rather high, $0.02 \AA$ and $2^{\circ}$, respectively, partly due to the large contribution of the iodine atom to the structure factors (Table 5).

The iodine atom is surrounded by six carbon atoms and one oxygen atom at distances about $3.9 \AA$. These distances are denoted by dashed lines in the packing diagram. The surrounding atoms belong to five different molecules of cryptostyline I.

Acknowledgements. The author wishes to thank Professors Arne Magnéli and Peder Kierkegaard for valuable comments on the manuscript. Thanks are also due to Drs. Ove Mattsson and Rolf Norrestam. This work has been supported by the Swedish Natural Science Research Council and the Tricentennial Fund of the Bank of Sweden.

\section{REFERENCES}

1. Leander, K., Lüning, B. and Ruusa, E. Acta Chem. Scand. 23 (1969) 244.

2. Bijvoet, J. M., Peerdeman, A. F. and van Bommel, A. J. Nature 168 (1951) 271.

3. Pauling, L. The Nature of the Chemical Bond, 3rd Ed., Cornell University Press, Ithaca 1960.

Received November 1, 1971. 